\title{
A Crowdsourcing Approach for Volunteering System
}

\author{
Nurulhasanah Mazlan, Sharifah Sakinah Syed Ahmad, Massila Kamalrudin, Ahmad Zaki \\ Abu Bakar \\ \{nurulhasanah@student.utem.edu.my,sakinah@utem.edu.my,massila@utem.edu.my\} \\ Faculty of Information and Communication Technology \\ Universiti Teknikal Malaysia Melaka (UTeM) \\ Melaka, Malaysia
}

\begin{abstract}
There are several versions of the volunteer management theory referenced in industry resources. Several organizations have developed organization-based systems designed to incorporate spontaneous volunteers. However, it can be difficult to find and recruit suitable candidates for volunteer organizations. Also, we still lack information on the process of crowdsourcing in volunteering perspective. This paper, we conduct a review of volunteering management systems and crowdsourcing approach. Based on the insights derived from this analysis, we identify some issues for future research. To solve this problem, we designed a framework for the crowdsourcing approach in volunteering system to automate the process of selection volunteers and match with the criteria of volunteers and tasks. Crowdsourcing is one of the best approaches to get more information and faster from the crowd and to be more precise with the requirement from beneficiaries. The implications of the findings for volunteering system are discussed, and future research directions suggested.
\end{abstract}

Keywords: volunteering system; volunteering matching; crowdsourcing; volunteering management; selection volunteer;

\section{Introduction}

Volunteering is an altruistic activity where members of a community contribute time, resources, and services to fulfill a community need without being paid financially. Every day, thousands of people are voluntarily giving their time, talent and resources to participate in activities that help people in need and to make the world a better place [1]. There is the almost endless supply of volunteers; the unlimited amount of meaningful volunteer works [2]. Volunteering is making an important contribution to society, for instance, supporting social services, sporting events, religious activities, etc. Volunteering is often done in terms to collaboratively or corporately accomplish the task.

Volunteer management system brings together potential volunteers with volunteering opportunities, allowing the scheduling, allocation, and execution of tasks, providing communication and coordination mechanisms for collaboration and cooperation and facilitating assessment and motivation strategies [3]. Recruitment and selection of volunteers are the most important process. However, the process to ensure the most appropriate match between volunteers and project are complex task. Collaboration with the crowd is the easiest 
way to get efficient and rapid results. Crowdsourcing is a technique that involves many volunteers to solve a problem that occurred. To ensure the crowdsourcing can impact on the volunteering, we need a lot of information. We still lack information on the process of crowdsourcing in volunteering perspective.

The objective of this research is to gain a better understanding of typical process on volunteering management system and crowdsourcing. We also focus on providing a crowdsourcing technique into volunteering system to find the best volunteers as the task solvers. The paper has been divided into four parts. Section 2 begins with the definition of volunteer, volunteer management, the definition of crowdsourcing and identify the interaction among the volunteers is needed with their criteria. Section 3 describes the design of a framework for crowdsourcing in volunteering system. Finally, Section 4 discusses our future work and concludes the paper.

\section{Related Work}

\subsection{Volunteers}

Volunteerism is defined as contributing one's time or talents for charitable, educational, social, political or other worthwhile purposes, usually in one's community, freely and without regard to compensation. Volunteering is the practice of people working on behalf of others without being motivated by financial or material gain [4] [5]. Volunteering may be done for other people or organizations, which can bring measurable benefits to the volunteer, individual beneficiaries, groups and organizations, communities, the environment and society as a whole. The variety of work done by these organizations and groups is enormous, and so the range of skills that potential volunteers can bring is almost limitless. Brett Williamson (Volunteering Australia Chief Executive Officer) [6] defines volunteering is time willingly given for the common good and without financial gain.

Like definitions found elsewhere, we can surmise that volunteering comprises activities that are unpaid and are entered into without compulsion. They freely offer up the time and service to help other people. Volunteerism fosters inclusiveness, empowerment, and sustainability evident in contributions to the physical, psychological, spiritual and economic well-being of the community.

\subsection{Volunteer Management}

Management can be described as making the most effective and efficient use of resources to achieve goals. A volunteer is a special kind of human resources, volunteer management subsystem contained in human resources management [7]. The volunteering management systems integrate and coordinate the core policies, processes, and activities that organization has in place for working with volunteers. It is made up of policies, procedures and work documents which control how the volunteer's program is implemented from day to day.

Zheng et al. [8] explain the volunteer management is to planning and implementation of planning carried out by a specific organization, by the need for volunteer activities. Event volunteers refer to those volunteers their time, energy, skills, and experience within the preparation and holding of the exhibition process, and try their best to the complete the task 
distributed to them. Several organizations have developed organization-based systems designed to rapidly incorporate spontaneous volunteers [9].

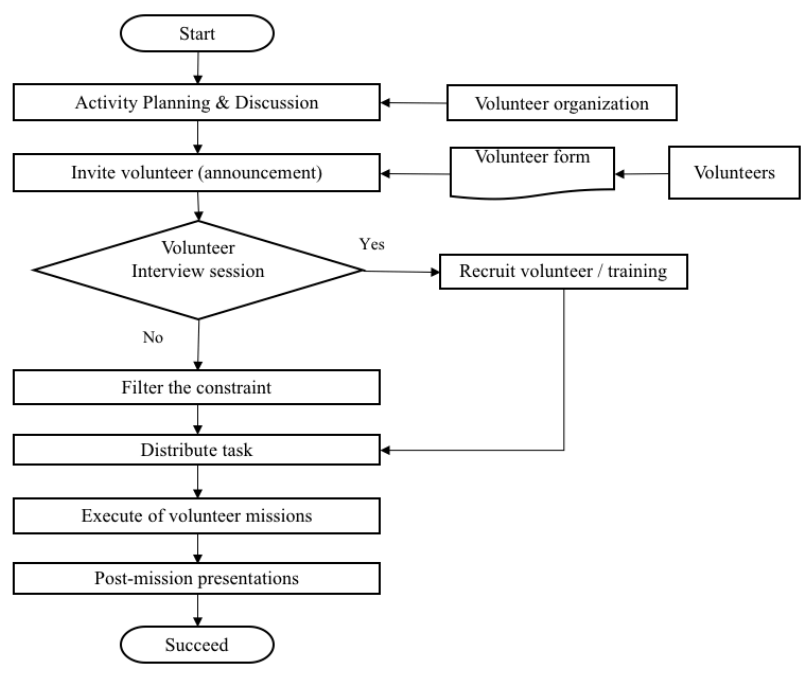

Fig. 1. Process of Volunteer Management

Figure 1 is the process of volunteering management in our perspective from the related study [10], [11] and interview session with several volunteer organization in Malaysia such as Mercy Malaysia, Spot Community, Projek Iqra', Hidayah Foundation Center (HFC) and several universities.

The process in Figure 1, the detailed procedures are started from volunteer organization makes planning and discussion to help beneficiary. Then organization makes announcement or publicity to attract volunteers to join the activities. They invite people using social media such as Facebook, website or phone. Volunteers whom interested need to register providing their profiles, including expertise, time available and location. Next, some organization needs interview session to filter the volunteer before proceed with the activity they do. If they have interviews, volunteers must have training sessions to qualify them to volunteer. The interview session provides not only an opportunity to talk to the potential volunteer about their background, skills but also to explore any doubts about the suitability of the candidate. If the organization no interview session, the volunteer filter based on constraints such as location, transportation, time availability, etc. The organization distributes their task when the volunteer was selected. Then the activities will be implemented. Finally, review the performance of volunteers and need to access the impact of the volunteer program.

As shown in Table 1, we summarize the volunteer management model from numerous versions. The procedure is to ensure that volunteers are aware of what is required of them and management have a more coordinated approach. Without the support of appropriate procedures, there is the risk that policy will not be effective. The different situation has different volunteering process such as Olympic and health care and also have a general process in general situation. 
Table 1. Process of Volunteer Management Based on Review Paper

\begin{tabular}{lccccc}
\hline \multicolumn{1}{c}{ Author } & \multicolumn{5}{c}{ Process } \\
\cline { 2 - 6 } & Planning & $\begin{array}{c}\text { Recruitment \& } \\
\text { Selection }\end{array}$ & $\begin{array}{c}\text { Induction \& } \\
\text { Training }\end{array}$ & $\begin{array}{c}\text { Supervision \& } \\
\text { Evaluation }\end{array}$ & Recognition \\
\hline Zheng et al.[8] & $/$ & $/$ & $/$ & $/$ & $/$ \\
Ducharme [12] & $/$ & $/$ & $/$ & $/$ & $/$ \\
Volunteer Glasgow & $/$ & $\mathrm{X}$ & $\mathrm{X}$ & $/$ & $/$ \\
Organization [5] & $/$ & $/$ & $/$ & $/$ & $/$ \\
Howard [13] & $/$ & $/$ & $/$ & $/$ & $/$ \\
Volunteer Australia [14] & $/$ & $/$ & $/$ & $/$ & \\
Studer \& von & & & & & $/$ \\
Schnurbein [15] & & &
\end{tabular}

According to Figure 1 and Table 1 in this paper indicated that recruitment and selection of volunteers are important to select the suitable volunteer based on their program. This process should be open, fair and competitive. We analysis the content of this work from this point of view to make clear the focus because we want to automate the process of selection, which can do with crowdsourcing and match with the criteria of volunteers.

\subsection{Recruitment and Selection for Volunteers}

Recruitment is to identifying and attracting its potential volunteers. Selecting volunteers are to find a good match between the prospective volunteer and the opportunity on offer. It is an attempt to find a strong blend where the person has the right skills, experience, and enthusiasm and the opportunity satisfy the needs and interests of the volunteer. Cvetkoska et al. [16] present the process of recruitment and selection in an institution for selecting students as volunteers using Analytic Hierarchy Process Method (AHP) for decision-making methods on several criteria. They determined seven criteria, which is Curricula Vitae (CV), computer skills, languages, student's motivation to volunteer, skills, creativity, and initiative. Similarly as Howard [13] concerned about recruitment and selection process. Criteria they take are a profile of volunteers, reason to be volunteers, kind of voluntary work, skills, and availability. However, they focus on parameters that familiar used by volunteer organizations.

Besides that, matching technique is an important part of recruitment and selection of volunteer because to find the suitable volunteer before assigning the task. Different researchers have proposed matching algorithm based on various situation with volunteer such as OWL-S matcher, RF-based localization techniques, Web2.0 style, size-specified community creation method and classification method ([17], [18], [19], [20], [21], [7]). Based on our review, we found that there is the various matching technique used in existing volunteering system. However, most of the techniques focus on to find the best volunteer with common characteristics and common using social network including Google calendar.

\subsection{Volunteer Management Systems and Platforms}

It has many volunteer management software products [22]. Out of these, we selected five volunteer management systems, which have been empirically evaluated as most used systems. First of all, the system Volgistics [23] allows non-profits can be customizing to fit their unique needs. For assignment matching compares the availability, characteristics, and preferences of 
each volunteer to selected assignment. VolunteerLocal [24] is a website used by volunteer coordinators to organize, recruit, schedule and communicate with their volunteers. The Registration System (TRS) [25] has been specifically designed for events. Voluntweeters [26] system use social theory about self-organizing by features of coordination within a setting of interaction. The GoVolunteer [27] system can search, express interest, shortlist opportunities and find short term, on-going and even one-off opportunities to support a wide range of cause. Travel2change [28] was launched as an online crowdsourcing platform in 2011 for volunteer travelers can connect with locals.

Most of the volunteer management systems are commercial, each pursuing different goals and exhibiting different functionality to support the phases of a volunteering process. System engineering is an interdisciplinary approach that uses a structured development process from concept through production and operation. The techniques of systems engineering can be applied to volunteer management system that is comprehensive and adaptable.

\subsection{Crowdsourcing}

Since the prevalence of crowdsourcing in industry and academia, several surveys about crowdsourcing for the general purpose were published. There is a growing interest in 'engaging the crowd' to identify or develop innovative solutions to public problems. Crowdsourcing coined in 2006 by Jeff Howe [29] in Wired Magazine article which is crowdsourcing is not a single strategy, but "an umbrella term for a highly varied group of approaches." Crowdsourcing is human collective intelligence use the Internet to collect idea, solve complex cognitive problems and build high-quality repositories by self-organizing agents around data and knowledge [30]. According to Kittur et al. [31], crowdsourcing refers to the use of small amounts of time and effort from a large number of individuals to solve large problems, thus creating a network of such individuals collaborating together.

The advantage of crowdsourcing is that the solutions to members of the audience are directly involved in the ideation and proposed solutions. For examples of crowdsourcing platforms are Amazon Mechanical Turk, the reCaptcha, Wikipedia and the ESP game (for image labeling). This technique has long been used in various aspects [32], [33]. Understanding the factors that contribute to project success is necessary for crowdsourcing's continued adoption, efficient and effective implementation, and maximizing its potential. Website statistics shared by crowdsourcing project teams provide evidence that the potential of the crowd can be significant [34].

\subsection{The Process of Crowdsourcing}

The sequence of crowdsourcing process is independent of the order in which a seeker (an organization or individual) decides on the individual characteristics when it plans the process. According to Kucherbaev et al. [35] crowdsourcing is not only deploying a set of simple micro-tasks on a given platform but may comprise several different tasks (writing, transcribing, classifying, aggregating, spell checking, and voting), actors (workers, and experts) and automated operations (data splitting, resolving redundancy of multiple delegations, making decisions, and synchronizing tasks). 


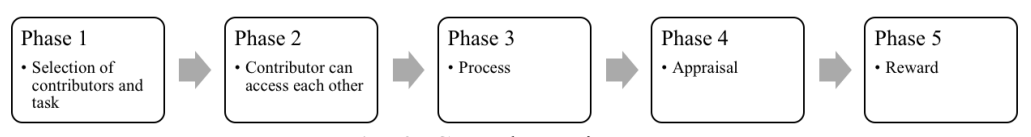

Fig. 2. Crowdsourcing Process

Based on the literature [36], [37], [38], they present the process in crowdsourcing then we summarize the process of crowdsourcing in Figure 2. The first phase is the process of choosing the right contributor for a specific task as outlined in a written job description. Besides that, some studies [20], [39], [40] involved a part of the process of crowdsourcing which is in the selection of contributors and task. Next step is contributor can access each other. In this process, contributors can be precise mechanisms to express their opinion on individual contributions. The third phase is how the crowd contribution within a crowdsourcing process is used by the crowdsourcing organization to achieve the desired outcome. The appraisal phase begins when the submitted ideas are clustered, rated, and best ideas will be rewarded. The final phase is a reward, determines how contributions are paid or otherwise compensated for their work.

Based on crowdsourcing process we can use this approach in volunteering management. This approach can get more information and faster from the crowd and be more precise with the requirement from beneficiaries.

\section{Proposed Framework for Volunteering System}

This section, we provide a general framework for volunteering system based on our findings. The design aims to solve the recruitment and selection suitable matches between volunteers, crowd and organizations.

\subsection{Framework}

From the user's point of view, there are three kinds of end users: volunteer organization (those who manage the volunteers and projects), the crowd (those who need help or suggest the project) and volunteers (those who freely offer up their time and service).

The system framework is illustrated in Figure 3, while Table 2 shows a procedure of the volunteering system by using crowdsourcing approach. We highlight that we involve crowdsourcing technique in volunteering system. 


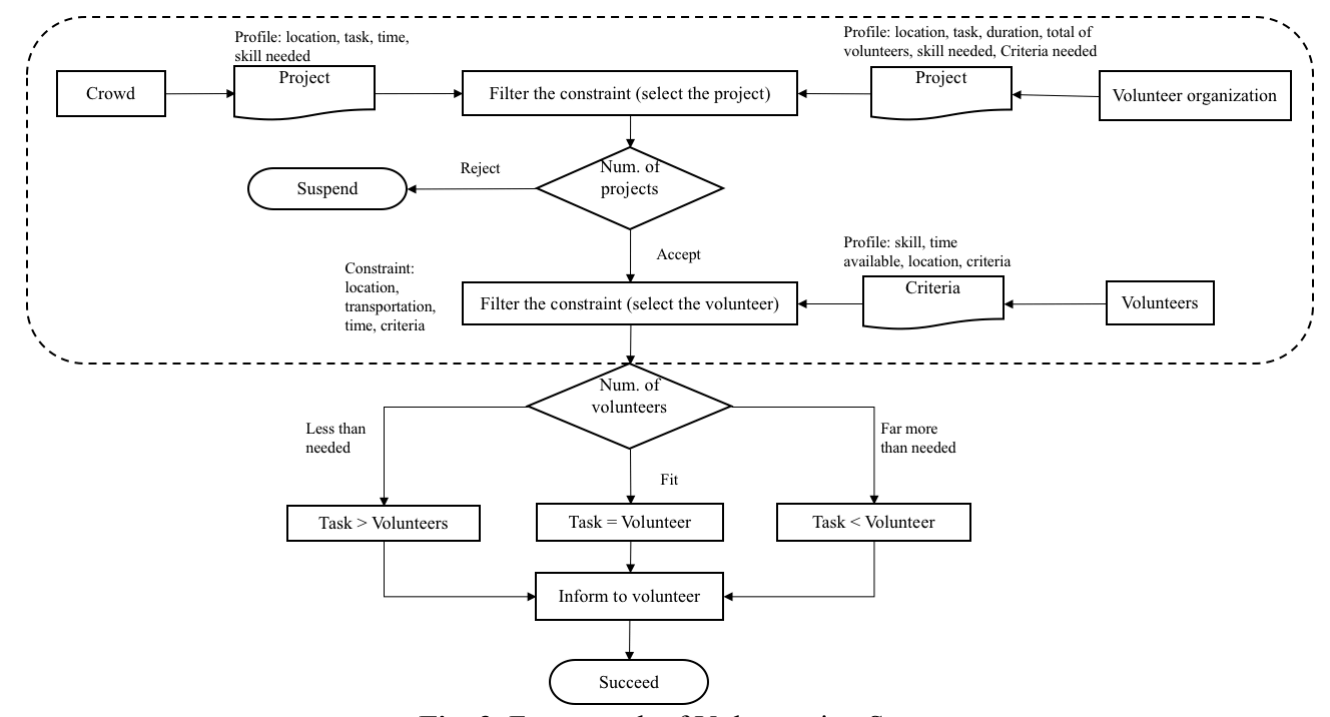

Fig. 3. Framework of Volunteering System

Table 2. The Procedure of Volunteering System

\begin{abstract}
Step 1: The crowd will give their suggestion of their place who need help or their know other people need help to system. The crowd comes from local people, sometimes volunteers who had been involved in volunteer activities or people around that concerned. They send requests to the system. A request is transformed into a project and decomposed into many tasks. A project has constraints like expertise needed, task, time, criteria needed, etc.
\end{abstract}

Step 2: Volunteer organization filters and investigate the place that suggests from the crowd. The system filter based on the requirement for the beneficiary.

Step 3: If volunteer organization accepts the project, the organization continues the project mission. The organization announces to volunteers have freely time and service to help. If volunteer organization reject the project, the project has to suspend for more demand from the crowd or have its constraint changed and to be assigned again or give other volunteer organization that suitable with their objective.

Step 4: Volunteers whom interested need to register by providing their profiles, including expertise, available, location, criteria they have, etc.

Step 5: The system matches volunteers with the task regarding expertise, available, location, transportation, and criteria.

Step 6: The project is accomplished through three situations: If the size of the candidate volunteers set fits with volunteers needed, then a task will give to a volunteer. Here "fit" means equal or a little larger for tolerance. If the number of volunteers is less than needed, then volunteers need to do more tasks in a project. If the number of volunteers is far more than needed, then a task does with many volunteers.

Step 7: After the system decides the volunteer task, the system informs to volunteers before execute the project mission.

The basic idea of our approach is use crowdsourcing approach in volunteering system. We used the crowd information to get the situation and project and volunteer also we get to solve the problem. We match the information from the crowd with suitable volunteer criteria. 
The criteria of volunteers depend on the project. The crowd has potential to help the people and give the information for a volunteer organization to manage. The volunteers also come from the crowd itself. For finding a fit between several volunteers (profile and criteria) and the crowd (specification criteria needed) certain planning strategies and matching algorithm requirements.

\subsection{Volunteer in Crowdsourcing}

Volunteer management research has been an important topic in the social science and wanted to combine with ICT. There are many commercial crowdsourcing platforms but rarely with consideration of users' structure and interaction, which is the concern of socially aware computing [41]. Tasks are just broadcast to an unknown group of solvers in the form of an open call for solutions. Since crowdsourcing faces people who are geographically distributed and with diverse backgrounds, social unawareness will be subject to unpredictable performance because of the arbitrary composition of users who happen to accept an offered task. However, in reality, a group's suitability for performing a task varies from group to group, not only depending on the attributes of the individuals involved such as knowledge, skills, location, and available time but also the relationships among them.

The development of volunteers is an investment for the city, so it is important that resources be provided to develop capacity and enable volunteers to play a bigger role in their community. An organizer invites a targeted group of people to perform certain tasks to create value. With the new internet technologies, all the emergence of social networks and collaboration software can be organized by online platforms. With the rise of successful crowdsourcing, can act as the intermediary between volunteer and local communities. The empower both, volunteer and local communities to create a collective impact, as they can directly communicate and collaborate via the platform. Therefore, we use crowdsourcing techniques to get the information quickly and accurately to facilitate the management of volunteers. There are few studies on volunteers regarding motivation on volunteerism or use the latest technology to help people [42],[4],[43],[20] but they focus on the specific situation. In this paper, we focus on finding a specific group of volunteers that can do a project efficiently and relevant with their task and can be used in any situation.

\section{Conclusion}

In this paper, we extracted volunteering and crowdsourcing features from various definitions that found in the literature. To achieve this goal, different domain (healthcare, emergency, disaster, etc.) were considered. In this investigation, the aim of this research is to contribute crowdsourcing approach for volunteering system. To this intent, we first laid out an argument as to the opportunities of such approaches by drawing upon research on the process of crowdsourcing. We proceeded by conducting a review of the academic literature on recruitment and selecting method and matching technique in various volunteering contexts. We proposed a framework of volunteering system that includes the crowdsourcing approach. Further research might investigate parameter for the volunteering system to construct the needed contents. We will complete the framework and develop a volunteering system likes our framework. We also would be evaluating our method in the real environment by user trials, especially the effectiveness of our approach. 
Acknowledgments. The authors would like to acknowledge Universiti Teknikal Malaysia Melaka (UTeM) and the Ministry of Education Malaysia for the resources as well as the MyBrain15 scholarship.

\section{References}

[1] P. A. Konwerski and H. W. Nashman, "Philantherapy : a benefit for personnel and organisations managing volunteers ( volunteer therapy )," Volunt. Action, vol. 9, no. 1, pp. 46-59, (2008).

[2] K. Allen, "From Motivation to Action Through Volunteer-Friendly Organizations," Int. J. Volunt. Adm., vol. 24, pp. 41-44, (2006).

[3] J. Schönböck, M. Raab, J. Altmann, E. Kapsammer, A. Kusel, B. Pröll, W. Retschitzegger, and W. Schwinger, "A Survey on Volunteer Management Systems," in 49th Hawaii International Conference on System Sciences (HICSS), (2016), pp. 767-776.

[4] Disability Equality (nw), "Good Practice in Supported Volunteering,” (2013).

[5] Volunteer Glasgow, "Glasgow's Strategic Volunteering Framework," (2010).

[6] The Centre for Volunteering, "New Definition of Volunteering in Australia," Definition for Volunteering 2015, no. 2, 30-Jul-2015.

[7] W. Chen, Y. Cheng, F. E. Sandnes, and C. Lee, "Finding Suitable Candidates : The Design of a Mobile Volunteering Matching System," in Human-Computer Interaction. Towards Mobile and Intelligent Interaction Environments, (2011), pp. 21-29.

[8] Y. (Lydia) Zheng, L. Deng, and M. Li, "Study on the Event Volunteer Management Based on the Service Blueprint," in 2009 International Conference on Information Management, Innovation Management and Industrial Engineering, (2009), pp. 408-411.

[9] L. S. Fernandez, "Volunteer Management System Design and Analysis for Disaster Response and Recovery," George Washington University, (2007).

[10] "Yayasan Sukarelawan Siswa (YSS).” [Online]. Available: https://prezi.com/_q0zqv0bja6g/yssprofile-english-ver2/.

[11] Division of Industry and Community Network Universiti Sains Malaysia, Volunteerism In Malaysia Fostering Civic Responsibility. Penerbit USM, (2013).

[12] E. G. Ducharme, "Our Foundation - The Basics of Volunteer Management," Can. J. Volunt. Resour. Manag., no. 20.1, pp. 2-4, (2012).

[13] B. W. Howard, "Managing volunteers," Aust. J. Emerg. Manag., vol. 14, no. 3, pp. 37-39, (1999).

[14] NHMRC, "Working with Volunteers and Managing Volunteer Programs in Health Care Settings," (2003).

[15] S. Studer and G. von Schnurbein, "Organizational Factors Affecting Volunteers: A Literature 
Review on Volunteer Coordination," Voluntas, vol. 24, no. 2, pp. 403-440, (2013).

[16] V. Cvetkoska, B. S. Gaber, and M. Sekulovska, "Recruitment and Selection of StudentVolunteers : a Multicriteria Methodology," Manag., no. 61, pp. 139-146, (2011).

[17] S. Hong, V. De Florio, G. Ning, and C. Blondia, "Service Matching in Online Community for Mutual Assisted Living," in Signal-Image Technologies and Internet-Based System, 2007. SITIS '07. Third International IEEE Conference on, (2007), vol. 80, no. Eu 15, pp. 427-433.

[18] C. C. Lo, S. C. Lin, S. P. Kuo, Y. C. Tseng, S. Y. Peng, S. M. Huang, Y. N. Hung, and C. F. Hung, "People help people: A pattern-matching localization with inputs from user community," ICS 2010 - Int. Comput. Symp., pp. 638-641, (2010).

[19] W. Shen and A. Doan, "Matching Schemas in Online Communities :," (2008), vol. 0, pp. 110 119.

[20] Z. Yu, D. Zhang, D. Yang, and G. Chen, "Selecting the Best Solvers: Toward Community Based Crowdsourcing for Disaster Management," in 2012 IEEE Asia-Pacific Services Computing Conference, (2012), pp. 271-277.

[21] D. Endo and K. Sugita, "A Volunteer Classification Method for Disaster Recovery," in 2010 International Conference on P2P, Parallel, Grid, Cloud and Internet Computing, (2010), pp. 436-439.

[22] “List of Volunteer Management Software.” [Online]. Available: http://www.coyotecommunications.com/tech/volmanage.html.

[23] "Volgistics." [Online]. Available: https://www.volgistics.com/.

[24] "VolunteerLocal." [Online]. Available: www.volunteerlocal.com.

[25] “TRS.” [Online]. Available: www.theregistrationsystem.com.

[26] K. Starbird and L. Palen, “"Voluntweeters,"” in Proceedings of the 2011 annual conference on Human factors in computing systems - CHI '11, (2011), p. 1071.

[27] K. Hughes, "Opportunities in your hand - GoVolunteer goes mobile," Volunteering Australia, Australia, 04-Dec-2015.

[28] T. Kohler, A. Stribl, and D. Stieger, "Innovation for Volunteer Travel: Using Crowdsourcing to Create Change," in Open Tourism, (2016), pp. 435-445.

[29] J. Howe, “The Rise of Crowdsourcing," Wired Magazine, no. 14, pp. 1-5, 2006.

[30] T. A. Büecheler, R. Lonigro, R. M. Füchslin, and R. Pfeifer, "Modeling and Simulating Crowdsourcing as a Complex Biological System : Human Crowds Manifesting Collective Intelligence on the Internet," in ECAL 2011. The Eleventh European Conference on the Synthesis and Simulation of Living Systems, (2011), pp. 109-116.

[31] A. Kittur, E. H. Chi, and B. Suh, "Crowdsourcing user studies with Mechanical Turk," in Proceeding of the twenty-sixth annual CHI conference on Human factors in computing systems - CHI '08, (2008), p. 453. 
[32] E. Estellés-Arolas and F. González-Ladrón-de-Guevara, “Towards an integrated crowdsourcing definition," J. Inf. Sci., vol. 38, pp. 1-22, (2012).

[33] M. Yuen and L. Chen, “A Survey of Human Computation Systems,” pp. 723-728, (2009).

[34] D. Mckinley, "How effectively are crowdsourcing websites supporting volunteer participation and quality contribution?,” New Zealand, (2013).

[35] P. Kucherbaev, F. Daniel, S. Tranquillini, and M. Marchese, "Crowdsourcing Processes: A Survey of Approaches and Opportunities," IEEE Internet Comput., vol. 20, no. 2, pp. 50-56, (2016).

[36] D. Geiger, S. Seedorf, T. Schulze, R. C. Nickerson, and M. Schader, "Managing the Crowd: Towards a Taxonomy of Crowdsourcing Processes," in Proceedings of the Seventeenth Americas Conference on Information Systems, Detroit, Michigan, (2011).

[37] L. Muhdi, M. Daiber, S. Friesike, and R. Boutellier, "Crowdsourcing : an alternative idea generation approach in the early innovation process phase of innovation," Int. J. Entrep. Innov. Manag., vol. 14, no. 4, pp. 315-332, (2011).

[38] Z. Li and Z. Hongjuan, "Research of crowdsourcing model based on case study," in Icsssm11, (2011), pp. 1-5.

[39] I. Lykourentzou, D. J. Vergados, K. Papadaki, and Y. Naudet, "Guided Crowdsourcing for Collective Work Coordination in Corporate Environments," in Computational Collective Intelligence. Technologies and Applications: 5th International Conference, ICCCI 2013, Craiova, Romania, September 11-13, 2013, Proceedings, vol. 8083 LNAI, C. B \vadiclva, N. T. Nguyen, and M. Brezovan, Eds. Berlin, Heidelberg: Springer Berlin Heidelberg, (2013), pp. 90 99.

[40] A. Kittur, J. V Nickerson, M. S. Bernstein, E. M. Gerber, A. Shaw, J. Zimmerman, M. Lease, and J. J. Horton, "The Future of Crowd Work," in Proceedings of the 2013 conference on Computer supported cooperative work (CSCW'13), (2013), pp. 1301-1317.

[41] P. Lukowicz, S. Pentland, and A. Ferscha, "From context awareness to socially aware computing," IEEE Pervasive Comput., vol. 11, no. 1, pp. 32-40, (2012).

[42] Volunteer Centre Dorset, “The Good Practice Guide To Volunteer Management," (2010).

[43] F. Fuchs-Kittowski and D. Faust, "Architecture of Mobile Crowdsourcing Systems," in Collaboration and Technology: 20th International Conference, CRIWG 2014, Santiago, Chile, September 7-10, 2014. Proceedings, N. Baloian, F. Burstein, H. Ogata, F. Santoro, and G. Zurita, Eds. Cham: Springer International Publishing, (2014), pp. 121-136. 